\title{
AS COMPETÊNCIAS SOCIOEMOCIONAIS NOS PROGRAMAS DE ENSINO
}

\author{
Atilla Ramos Leite*, Telma Vinha, Warley G. Correa
}

\begin{abstract}
Resumo
Nos últimos anos as instituições acadêmicas e educacionais defendem a importância de a escola desenvolver, além das cognitivas, as competências socioemocionais, tais como, o engajamento, a expressão de sentimentos, a colaboração, a resiliência, a empatia e o autocontrole. Tais competências contribuem para a aprendizagem dos conteúdos e para o bem-estar psíquico e no êxito pessoal e profissional. Em vista disso, o presente estudo do tipo estado do conhecimento teve como objetivo realizar um levantamento bibliográfico dos programas de intervenção educacionais, desenvolvidos entre 2000 e 2017, que visam favorecer o desenvolvimento das competências socioemocionais dos estudantes das séries finais do Ensino Fundamental (6ำ ao $9^{\circ}$ ano). Após busca em base de dados nacionais e internacionais e da análise de 309 trabalhos encontrados, foram identificados 37 artigos em Português, Inglês e Espanhol. A análise desses estudos mostraram que, em geral, os programas são desenvolvidos em sessões/aulas semanais com os alunos envolvendo habilidades emocionais e sociais, a maior parte das avaliações dos programas empregadas foi experimental ou quase-experimental e os resultados dessas avaliações indicaram benefícios expressivos para os participantes, como aumento no engajamento e na motivação e redução nas evasões.
\end{abstract}

\section{Palavras-chave:}

Competências socioemocionais; intervenção escolar; adolescentes.

\section{Introdução}

O aprendizado socioemocional é o processo por meio do qual aprendemos a reconhecer e expressar emoções, cuidar dos outros, tomar boas decisões, comportar-se com responsabilidade, desenvolver comportamentos mais assertivos e colaborativos. Esse desenvolvimento interfere na qualidade dos relacionamentos, na aprendizagem e na forma como a pessoa lida com os conflitos, afetando os resultados da vida pessoal e profissional. A nova Base Nacional Comum Curricular, inclui tais competências como essenciais de serem trabalhadas pela escola. São consideradas como direitos de aprendizagem e desenvolvimento. Devido a relevância e atualidade dessa temática esse estudo, do tipo estado do conhecimento, teve como objetivo realizar um levantamento bibliográfico dos programas de intervenção educacionais, desenvolvidos entre 2000 e 2017, que visam favorecer o desenvolvimento das competências socioemocionais dos estudantes dos $6^{\circ}$ ao 9 ano do Ensino Fundamental.

\section{Resultados e Discussão}

Com o uso de descritores foram realizadas buscas em bases de dados nacionais e internacionais sendo encontrados 309 trabalhados. A partir da leitura dos resumos foi feita uma segunda classificação em que selecionamos 123 artigos. Em seguida, foram analisados os métodos, resultados e outros elementos desses artigos avaliando se realmente referiam-se à programas escolares sobre competências socioemocionais em adolescentes. Os resultados foram comparados com os encontrados por um juiz independente, especialista na área, obtendo $100 \%$ de concordância. Após todo esse processo foram identificados 37 artigos diretamente relacionados ao nosso objetivo.

Em geral os trabalhos avaliados referem-se à programas já existentes (como o Atitude Positiva e o Second Step Middle School Programa) ou foram elaborados/implantados pelos próprios pesquisadores. As habilidades que mais recorrentes nos programas foram: resolução de conflitos; autoestima; consciência social; autoconsciência; reconhecimento das emoções; alfabetização emocional; assertividade; habilidades de estabelecer relacionamentos saudáveis; autocontrole e empatia. A maioria das intervenções ocorriam durante o período de aula, em momentos de 30-40 minutos, uma vez por semana, exclusivamente destinados ao trabalho com essas habilidades. A quantidade das aulas/sessões foi variada, em média, de 10 a 15.

A maior parte das avaliações empregadas é experimental ou quase-experimental utilizando questionários e autorrelatos. Os resultados encontrados nas avaliações dos programas indicaram benefícios expressivos para alunos com baixo desempenho e também com problemas de comportamento, se comparados com estudantes pertencentes às escolas que não desenvolvem programas nessa área. Mostram também aumento no engajamento e na motivação de alunos que participam de tais propostas. Em curto prazo, um dos impactos mais recorrente é a redução das evasões.

\section{Conclusões}

Os artigos encontrados confirmam ser relevante a escola cuidar, desde cedo, do desenvolvimento das competências socioemocionais visando uma formação mais integral do ser humano. Contudo, esse trabalho deve ir além de momentos específicos em que o ensino de tais habilidades é realizado. A construção de tais competências é decorrente de um longo processo de desenvolvimento e aprendizagem, que ocorre gradualmente, por meio de atos cotidianos do professor que as estimulem, de uma série de experiências efetivamente vivenciadas, de ações intencionalmente organizadas e sistêmicas, de reflexão contínua, exercício do diálogo, amadurecimento das relações e coerência nos procedimentos empregados.

\section{Agradecimentos}

Agradecemos ao Conselho Nacional de Desenvolvimento Científico e Tecnológico (CNPq) pelo apoio financeiro. 